\title{
Intervention in Autism: Social Engagement Implemented by Caregivers ${ }^{1}$
}

\author{
Adrine Carvalho dos Santos ${ }^{2}$ \\ Universidade Federal do Pará, \\ Belém-PA, Brazil \\ Ivete Furtado Ribeiro \\ Universidade Federal do Pará, \\ Belém-PA, Brazil
}

\author{
Marilice Fernandes Garotti \\ Universidade Federal do Pará, \\ Belém-PA, Brazil \\ Cleonice Alves Bosa \\ Universidade Federal do Rio Grande \\ do Sul, Porto Alegre-RS, Brazil
}

\begin{abstract}
To become involved in states of social engagement with their caregivers is a core deficit of children with autism. This study verified the effectiveness of an intervention with caregivers for the promotion of social engagement in their children with autism. The interactions of seven dyads were video recorded before, during and after the intervention in order to record the duration of eleven states of the children' attention engagement, coded as social engagement (SE) or non-social engagement (NSE). Eight hours of intervention were divided into meetings with all the caregivers and into individualized monitoring. After the intervention, significant differences were observed regarding the increase of SE and in the decrease of NSE and these gains were maintained at follow-up. The increase in SE was positively associated with the degree of caregivers' adherence to the treatment. We conclude that short duration interventions can qualify caregivers as competent mediators to increase social engagements.
\end{abstract}

Keywords: autism, social interaction, caregivers

\section{Intervenção em Autismo: Engajamento Social Implementado por Cuidadores}

Resumo: Envolver-se em estados de engajamento social com seus cuidadores é um déficit central de crianças com autismo. Este estudo verificou a efetividade de uma intervenção com cuidadores para a promoção de engajamento social em suas crianças com autismo. As interações de sete díades foram filmadas antes, durante e após a intervenção para registro da duração de onze estados de engajamento da atenção infantil, categorizados como social (ES) ou não social (ENS). Oito horas de intervenção foram divididas em encontros grupais e em monitoramentos individuais. Após a intervenção foram observadas diferenças significativas no aumento de ES e na diminuição de ENS e esses ganhos foram mantidos na avaliação de seguimento. O aumento em ES estava positivamente associado ao grau de adesão das cuidadoras ao tratamento. Concluímos que intervenções de curta duração podem capacitar cuidadores como mediadores competentes para aumentar engajamentos sociais.

Palavras-chave: autismo, interação social, cuidadores

\section{Intervención en Autismo: Engajamento Social Implementada por Cuidadores}

Resumen: Participar en estados de engajamento social con sus cuidadores es un déficit central de niños con autismo. Este estudio verificó la efectividad de una intervención con cuidadores para la promoción de engajamento social en sus niños con autismo. Las interacciones de siete díades fueron filmadas antes, durante y después de la intervención para registro de la duración de once estados de engajamento de la atención infantil, categorizados como social (ES) o no social (ENS). Ocho horas de intervención fueron divididas en encuentros grupales y en monitoreos individuales. Tras la intervención fueron observadas diferencias significativas en el aumento de ES y en la disminución de ENS y esas ganancias fueron mantenidas en la evaluación de seguimiento. El aumento en ES estaba positivamente asociado al grado de adhesión de las cuidadoras al tratamiento. Concluimos que intervenciones de corta duración pueden capacitar cuidadores como mediadores competentes para aumentar engajamentos sociales.

Palabras clave: autismo, interacción social, cuidadores

\footnotetext{
1 Paper derivative of the master's thesis of the first author, under the supervision of the second, defended in 2013, in the Graduate Program in Theory and Behavioral Research of the Universidade Federal do Pará. Acknowledgement: We thank the following scientific initiation students: Ana Paula Soares, Joyce Leal, Lorraine Calandrini, and Teresa Rocha, who contributed to the data collection for this study.

Support: Coordination for the Improvement of Higher Education Personnel (CAPES).

2 Correspondence address:

Adrine Carvalho dos Santos. Universidade Federal do Pará. Campus Universitário do Guamá. Rua Augusto Corrêa, 01. CEP 66075-110. Belém-PA, Brazil. E-mail: adrinecsantos@gmail.com
}

Deficits in joint attention (JA), defined as the use of gestures and eye contact to direct the attention of another person toward objects/events and toward oneself in order to share interesting or pleasurable experiences (Mundy \& Newell, 2007), are the main predictors of autism (Charman, 2003; Jones, 2009). Children diagnosed with autism, when compared to their peers with developmental delays or with typical development, show significantly less alternation of looking between the object and social partner 
to obtain attention and initiate joint activities, less visual contact during social interactions (Charman, 2003; Jones \& Klin, 2013), and difficulties in synchronizing the social smile and look into one communicative action (Adamson, Deckner, \& Bakeman, 2010). They also present difficulties in orienting themselves toward the focus of attention of the other person (e. g., to follow the direction of the look or pointing of the social partner), both for "come and participate" in an ongoing activity, and during social interactions, to maintain them (Leekam \& Ramsden, 2006).

The accumulation of evidence on the importance of JA for the development of language (Charman, 2003), engagement and social competence (Mundy \& Sigman, 2006), positive affect (Lawton \& Kasari, 2012) and social cognition (Mundy \& Newell, 2007), has stimulated the production of various intervention programs in autism, mainly to develop communication and language. In some programs, the JA skills (to respond to and/or initiate social interactions) were taught directly to the child by the researcher (Meindl \& Cannella-Malone, 2011; White et al., 2011); while others focused on the primary caregivers, usually the mothers, for the implementation of these skills (Aldred, Green, \& Adams, 2004; Kasari, Gulsrud, Wong, Kwon, \& Locke, 2010; McConachie, Randle, Hammal, \& Le Couteur, 2005; Vismara, Colombi, \& Roger, 2009).

These studies varied regarding the skills taught to the caregivers, for example, in the structuring of the play environment, the creation of new routines with opportunities for the children to initiate and respond to interactions (Ingersoll \& Wainer, 2013; McConachie et al., 2005; Vismara et al., 2009), replacement of the intrusive verbal behavior with other behavior that facilitated communication and the signaling of pragmatic intentions (Aldred et al., 2004), among others. Overall, the results indicated that children whose parents had received specific training showed significant improvements in communication and socialization (Tonge, Brereton, Kiomall, Mackinnon, \& Rinehart, 2014), in reciprocal social interaction, in social responses and spontaneous initiation of interactions (Aldred et al., 2004), and in functional verbal and social initiative expression (Vismara et al., 2009).

However, the different activities taught to parents in different studies, together with the diversity of skills measured to refer JA (e. g., to alternate the look between the object and the other person, to point to objects, to display objects, to initiate and/or respond to social interactions etc.), make it difficult to identify critical elements of the procedures associated with the promotion of changes, especially in JA. Furthermore, in the majority of the studies, shared attention was defined as a set of individual skills of the child, placing the need for social interactions for the occurrence of those skills in the background (Kasari et al., 2010; Racine \& Carpendale, 2007).

Considering the importance of joint activities for the development of joint attention, Bakeman and Adamson (1984) identified five child attention engagement states when interacting with the primary caregiver. The states ranged from the absence of child attention toward the object and/or person (state of non engagement), to engagements involving the coordination of the attention of the child and caregiver to share a common object/event (coordinated joint engagement), which could be initiated by the child or by the partner. The states can also be specified through the infusion of symbols (Adamson, Bakeman, \& Deckner, 2004), characterized by the verbalizations of the child, or by specific responses to the speech of the caregiver, indicating comprehension, or by the occurrence of symbolic play.

There is also an intermediate state of attention, adult supported joint engagement (SJE) in which child and caregiver work actively on a common object, even though the child does not show explicit signs of recognition of the presence of the adult, however, looks or smiles at him/her. The importance of this state is that its occurrence during the interaction can provide the child with an implicit social context, and the adult with opportunities to establish patterns of action that may lead to the development of new forms of referential communication in children with typical development (Adamson et al., 2004).

Using the model proposed by Adamson et al. (2004), Kasari et al. (2010) developed a program implemented by caregivers to promote joint engagement in children with autism. The intervention consisted of ten modules in which responding to the initiatives of the caregiver and initiating interactions with the caregiver were modeled in structured play situations. The procedures involved the teaching of developmental principles of parental responsiveness and methods for facilitating the interactions, as well as aspects for the analysis of the applied behavior. Each caregiver-child dyad attended the laboratory three times a week, for eight weeks, for the intervention sessions. In each session (of approximately 30 minutes), a trained interventionist provided the caregiver with direct instructions regarding the topics, modeled and guided the practice during the interactions, and provided feedback at the end of the meeting. The results indicated that the children of the intervention group, when compared to those of a group waiting for the intervention (without training of the caregivers), significantly decreased the duration of engagement with the object and significantly increased the length of engagement with the caregiver. These gains were maintained in the follow-up evaluation, performed at 12 months. The authors concluded that the caregivers conducted the intervention with high levels of adherence to the strategies, and that they promoted the increase of joint engagement in their children.

Since children with autism tend to have more interest in objects, are less socially oriented, and resist more the social aspects of the context of interaction than their peers with Down syndrome and typical development (Adamson et al., 2010), interventions that promote the increase of social engagement of the attention, especially of SJE, may be particularly effective, as they create opportunities for situations in 
which the adult can attract the attention of the child to the object and then organize and direct the actions of the child in joint activities. Considering this perspective, the present study modified the intervention program used by Kasari et al. (2010) and verified its effectiveness when applied with a group of Brazilian caregivers. As well as the same theoretical and methodological approach toward the child's attention engagement states, the proposed intervention used the same content as the teaching modules of Kasari et al. designed to increase the responsiveness of the caregiver and facilitate interactions, however modified the number and form of administration of these learning modules. In a meta-analysis focusing on sensitivity and attachment, Bakermans-Kranenburg, van IJzendoorn and Juffer (2003) concluded that interventions with fewer than 16 sessions and the use of video-feedback were more effective. Based on this information, the duration of the intervention was reduced to slightly more than eight hours, divided into eight meetings. In addition, the video-feedback technique was introduced in the first two monitoring sessions, and the observations of the caregiver-child interaction occurred in the free play context in the homes of the dyads. The intervention of Kasari et al. (2010) had duration of approximately 12 hours, divided into 24 sessions and conducted in the laboratory, and the caregiver-child interactions were performed in the context of structured play.

According to Barton and Fettig (2013), the analysis of the effectiveness of an intervention mediated by caregivers includes, in addition to the results documented for the child, the analysis of factors that affect these results, such as the fidelity of the parents in the use of the strategies and the procedures used by the researcher to ensure parental fidelity (fidelity implementation). From this background, the present study aimed to evaluate the effectiveness of an intervention with caregivers to promote social engagement in their children with autism. It was assumed that if the intervention was effective, the results observed with the children after the intervention implemented by the caregivers would present a significant increase in the duration of the social engagement and a similarly significant decrease in the duration of the nonsocial engagement when compared to the baseline. It was also assumed that these changes would be observed in the follow-up evaluation and would be positively associated with the level of adherence to the intervention by the caregivers.

\section{Method}

\section{Participants}

Participants were seven caregivers and their children with autism, aged between 47 and 67 months $(M=51.14 ; S D=8.76)$ at the start of the study. All guardians of children up to 72 months of age, who were attended at the Autism Outpatient Clinic of a university hospital, were invited to participate in a meeting, in which the aims and procedures of the study were explained. The caregivers that were interested and had availability to participate completed a registration form and were then recruited by the researcher. The diagnosis was carried by physicians independent of the research team and was based on the DSM-IV or ICD-10 and on the authorized Brazilian version of the Childhood Autism Rating Scale - CARS (Pereira, 2007). The children had been diagnosed, with a mean of 36 months of age $(S D=6.0)$, and presented no other associated disabilities (motor, visual, auditory and/or multiple) and/or genetic syndromes (Down syndrome, Fragile $\mathrm{X}$ syndrome, among others). Children of dyads D2, D3, D6 and D7 were diagnosed with severe autism, and the others with mild-moderate autism.

With the exception of one child (D2), six attended the kindergarten of a regular school and all attended one or more specialized care services (pedagogy, speech therapy, occupational therapy, psychology) for between 15 (D2) and 300 (D6) minutes per week. The majority of the children (71.4\%) were primogenitus (D1, D3, D4, D5, D7) and one of these (D3) had a twin without autism. Four children were verbal (D1, D2, D5, D7) and the pragmatic language ranged between .5 (D5) and 3.4 (D4) communicative acts per minute.

The caregivers, six mothers and one nanny (D7), had a mean age of 33 years $(S D=4.28)$, five had completed high school education and two, higher education. The mean family income reported was RS\$2,924.00 ( $S D=\mathrm{RS} \$ 1,938.65)$ and two mothers (D4 and D5) performed paid work outside the home. The D5 dyad composed an extended mononuclear family, while the others composed nuclear families (D2, D3, D6) and extended nuclear families (D1, D4, D7).

\section{Instruments}

Inventory of Other Care Services (OCS). This lists the weekly duration and the nature of other programs and therapies administered to the children when they started and finished their participation in this study.

Pragmatic Language Test. Evaluates expressive language into two categories (verbal and nonverbal children) at the start of the study, and pragmatic language, indicated by the number of communicative acts of the child during the interaction with the caregiver, at baseline and after the intervention (10 minutes each phase). The evaluation refers to part D of the ABFW Childhood Language Test (Andrade, Béfi-Lopes, Fernandes, \& Wertzner, 2011), developed and validated in Brazil. It is scored based on video recordings of the child-caregiver interaction.

Scale of Adherence to the Training (SAT). At the end of follow-up evaluation, the caregivers indicated their degree of adherence to the intervention program according to a 5-point Likert scale ( $1=$ lowest level of adherence; $5=$ highest level of adherence).

Protocol of observation of the attention engagement states of the child. The protocol coded the attention of the child during the interactions with the caregiver according to the 11 engagement states proposed by Adamson et al. (2004). 
For the analyzes these states were grouped into two categories defined on the basis of the involvement or not of the social partner. Non-social engagement (NSE) included the states unengaged (UE), registered when the child was not involved with the specific person or object; onlooking (OL), in which the child only watched the activity of the partner; object engagement (OE), when the child was engaged only with the object and OE-S, when the use of language or symbolic gestures was observed with no clear external reference; and symbol only engagement (SOE), in which the child used language or symbolic gesture without direction toward the social partner or referred object. Social engagement (SE) included person engagement (PE), when the child engaged only with the person; adult supported joint engagement (SJE) in which the dyad was actively involved with the same object, however, the child did not explicitly recognize the partner's physical presence; and coordinated joint engagement (CJE), registered when the child, in addition to coordinating its attention between the partner and the shared object for at least 20 seconds, alternated its gaze between the object and the partner's face. When there was symbol infusion in any of these states, the categories were recorded as PE-S, SJE-S and CJE-S.

\section{Procedure}

Data collection. Using a within subject design, in which the subjects act as their own control, the study was conducted in four phases, with three evaluation phases (baseline, post-intervention and follow-up) and one intervention phase. In all the phases the caregiver-child interactions were completely filmed.

Evaluation phases. At baseline (Phase 1, BL), each caregiver attended the laboratory and responded to the sociodemographic interview, to the anamnesis and to the Inventory of Other Care Services (OCS). In a second visit to the laboratory, the observation of the caregiver-child interaction at baseline (10 minutes) was conducted. The session was held in an appropriate room, with the provision of objects (miniatures of musical instruments, cars, machine shop tools, kitchen sets, hair brushes and tooth brushes, as well as dolls and children's books, etc.) that allowed exploratory, functional and symbolic play. The caregivers were asked to act with the child as they would in their home. In the post-intervention evaluation (Phase 3, Post), the caregiver and child returned to the laboratory for the performance of another observation session, which also served to assess the pragmatic language after the intervention. In the follow-up evaluation (Phase 4, FU) the goal was to verify whether the gains obtained with the intervention were still maintained three months after its finalization. In this phase the researcher made the final visit to the residences of the families for an observation of the interaction session and to obtain data regarding adherence to the training (SAT).

The intervention with the caregivers (Phase 2) lasted two months and the course content was divided into four modules, taught with the caregivers fortnightly in four group meetings (GMs) of 90 minutes each. The GMs were held in a classroom of the university equipped with a projector, which enabled the display of illustrative clips of the different items of each theme. At the beginning of each meeting the caregivers received a booklet summarizing the main items of the module, facilitating the clarification of doubts during the GM. The modules covered the following themes: organization of the play environment, selection of toys and importance of environmental exploitation by the child (Module 1); organization of the play, identification and expansion of the child's focus of attention (Module 2); identification, expansion and maintenance of the child's social engagement states (Module 3); and identification, modeling and generalization of the child's skills in initiating joint activities (Module 4).

Between each GM, the dyads received individualized home monitoring (IM), in which the researcher checked and clarified the difficulties faced by the caregiver when using the strategies presented and discussed in the previous GM. This initial step could last 15 to 20 minutes, depending on the caregiver, and was followed by a caregiver-child interaction session lasting 10 minutes. During the first two IM sessions (IM1 and IM2), the video-feedback technique was used after the initial step. This procedure lasted approximately 15 minutes. An advantage of the use of video-feedback is the possibility of intervening in the social behavior without interrupting the ongoing interaction (State \& Kern, 2012). Thus, the caregivers could observe specific characteristics of their interaction with the child in the contexts in which they occurred, and compare them with the contents of the previous group meeting.

Data analysis. For all analyzes the duration, in seconds, of each attention engagement state was considered. The videos with the interactions (sessions) were analyzed to record the start and end of each of the child's attention engagement states. The first 10 minutes of the baseline and post-intervention interactions, the final five minutes of each individual monitoring session and the final eight minutes of the follow-up evaluation were analyzed. The video analysis was performed using the Transana 2.53 program (Woods, 2013). The SPSS 18.0 program was used for the descriptive analyses (mean and standard deviation), for paired comparisons between phases (Wilcoxon) and to verify associations between variables (Spearman).

Level of concordance between observers. Two independent observers blinded to the study phases analyzed all the video clips of the baseline and post-intervention sessions, $50 \%$ of the video clips of each individual monitoring session and $25 \%$ of the video clips of each follow-up session. The video clips analyzed were selected at random. Disagreements about the coded categories were discussed and the respective video clips reanalyzed. After the reanalysis, the level of concordance ranged from $75 \%$ (for OL and OE) to $100 \%$ (for the other engagement states). 


\section{Ethical Considerations}

The study was approved by the Research Ethics Committee of the Núcleo de Medicina Tropical of the Universidade Federal do Pará (CEP-NMT/UFPA - Protocol no. 334.526 / CAAE: 08831312.1.0000.5172) and all the guardians signed the Informed Consent (IC) form, after a meeting to clarify the aims and procedures of the study.

\section{Results}

Table 1 presents the descriptive data for the engagement states observed in the three evaluation phases and the probabilities associated with the differences between the baseline and post-intervention. The Wilcoxon test showed that after the intervention the dyads spent significantly longer in Social Engagement (SE) and significantly less time in Non-Social Engagement (NSE) compared with their respective baselines. No significant differences were observed between the evaluations of SE or NSE at post-intervention and follow-up. However, the comparison between baseline and the follow-up evaluation revealed significant differences both in the increase of SE $(z=-2.20, p=.028)$ and the reduction of NSE $(z=-2.20, p=.028)$, indicating that the gains obtained from the intervention were maintained three months after its final ization.

The mean duration of the main component states of SE (SJE SJE-S, CJE) and NSE (UE, OE) were also evaluated over the three evaluation phases. During the intervention there was a significant increase in adult supported joint engagement (SJE), of SJE involving symbol infusion (SJE-S), and a significant decrease in object engagement $(\mathrm{OE})$, while the coordinated joint engagement (CJE) and unengaged (UE) states remained stable. Three months after the end of the intervention, stability was observed in the NSE components, as well as a reversal of the SE pattern: SJE and SJE-S decreased and CJE increased.

The relationships between the engagement states (SE and NSE), the individual variables of the child (diagnosis, age, presence/absence of expressive language, pragmatic language) and the time spent in other care services (OCS) were also analyzed. The presence of spoken language (evaluated at baseline) was positively associated with the duration of the SE in the baseline $(.87 ; p<.05)$ and follow-up $(.83 ; p<.05)$ phases, and the SJE-S in the post-intervention $(.87 ; p<.05)$ phase, suggesting that expressive language is a relevant variable for the establishment of social engagement. Pragmatic language, in turn, was strongly associated only with CJE in the post-intervention $(.80 ; p<.05)$ phase. Regarding the participation of the children in other care services (OCS), it was observed that there was a strong negative association with the duration of the $\mathrm{SE}$ at baseline $(-.77 ; p<.05)$ and at post-intervention $(-.92 ; p<.01)$, and a strong positive association with the unengaged (UE) state in the post-intervention $(.81 ; p<.05)$ and follow-up $(.81 ; p<.05)$ evaluations. These relationships suggest that time spent in different care services did not contribute to the increase in the SE of the dyads. Interestingly, UE was also positively associated with the age of the child $(.85 ; p<.01)$, i.e., the older children presented less engagement with the social or physical environment.

Figure 1 shows the attention engagement patterns observed for each dyad in the evaluation phases. At baseline, the dyads spent the majority of the interaction in the UE (D3), and OE (D2, D4, D5, D6, D7) states, or alternating between these two states (D1). All the dyads presented adult supported joint engagement (SJE), and for five of them (D2, D3, D4, D5, D6) the duration varied between $10.9 \%$ and $17 \%$ of the total time of the interactions; for the remaining two, SJE occupied $36.6 \%$ (D7) and $48.6 \%$ (D1) of the interaction. After the intervention, the dyads decreased OE, and only three (D1, D2, D7) decreased UE. The SJE increased for D3, D4, D5, D6 and D7; for D2 there was a substantial increase in SJE with symbol infusion (SJE-S), and for D1, SJE-S was documented for the first time. The SJE state with symbol infusion (SJE-S) also emerged, with shorter duration, for D4, D5 and D7. There was the emergence of other states not observed at baseline, with coordinated joint engagement

Table 1

Mean (M), Standard-Deviation (SD) of the Duration (Seconds) of the Engagement States in the Three Evaluation Phases and Probabilities Associated With Differences Between Baseline and Post-Intervention

\begin{tabular}{|c|c|c|c|c|c|c|c|c|}
\hline \multirow{2}{*}{ Engagement state } & \multicolumn{2}{|c|}{$\begin{array}{c}\text { Baseline } \\
(N=7)\end{array}$} & \multicolumn{2}{|c|}{$\begin{array}{c}\text { Post-intervention } \\
(N=7)\end{array}$} & \multicolumn{2}{|c|}{$\begin{array}{c}\text { Follow-up } \\
(N=6)\end{array}$} & \multirow[t]{2}{*}{$z^{\mathrm{a}}$} & \multirow[t]{2}{*}{$p$} \\
\hline & $M$ & $S D$ & $M$ & $S D$ & $M$ & $S D$ & & \\
\hline NSE & 455.14 & 83.22 & 297.14 & 152.64 & 202.87 & 146.06 & -2.37 & .02 \\
\hline SE & 144.86 & 83.22 & 302.86 & 152.64 & 277.13 & 146.06 & -2.37 & .02 \\
\hline UE & 133.56 & 98.78 & 131.58 & 103.20 & 131.07 & 164.08 & -0.17 & ns \\
\hline $\mathrm{OE}$ & 302.84 & 122.74 & 158.94 & 92.01 & 147.04 & 106.24 & -2.37 & .02 \\
\hline SJE & 143.61 & 81.80 & 290.36 & 150.89 & 149.33 & 142.38 & -2.37 & .02 \\
\hline SJE-S & 10.81 & 28.61 & 122.51 & 197.17 & 76.30 & 159.40 & -2.02 & .04 \\
\hline CJE & 1.26 & 3.33 & 8.57 & 19.53 & 83.95 & 187.68 & -0.53 & Ns \\
\hline
\end{tabular}

Note. $\mathrm{SE}=$ social engagement; $\mathrm{NSE}=$ non-social engagement; UE = unengaged; OE = object engagement; SJE = supported joint engagement; SJE-S = supported joint engagement and symbol infusion; CJE $=$ coordinated joint engagement. ${ }^{a}$ Results of the Wilcoxon test between baseline and post-intervention. 
(CJE) for D1 and D4; person engagement (PE) for D1 and D3; OE with symbol infusion (OE-S) for D1 and symbol only engagement (SOE) for D2. In follow-up evaluation, D1 spent $97 \%$ of the time in CJE-S, and D2, $82.9 \%$ of the time in SJE-S. The D3 and D5 dyads showed slight increases in the duration of SJE, while D4 showed a slight decrease in the duration of this state with respect to the post-intervention phase. However, the main part of the interaction of these dyads was characterized by UE (D3, D4) and OE (D5). For D7, more than half of the session was characterized by PE, however, SJE followed by CJE were observed at the end of the session. The D6 dyad did not participate in this phase due to lack of time on behalf of the child.

With regard to the respective baselines, with the exception of D3, the dyads presented an increase in the duration of the episodes of SE throughout the monitoring. This increase was gradual and at the end of intervention (IM4), of the six dyads who participated in this stage, three (D1, D4, D6) presented SE in over $85 \%$ of the time of the observation session; for the other dyads SE was below $50 \%$, with the duration of these engagements being even greater than at baseline for D5 and D7. Of the five caregivers who participated in the video-feedback procedure in IM1 and IM2, four spent between 98\% (D2) and $100 \%$ (D1, D6, D7) of the interaction time with their children in SE at the end of IM2.

Regarding the group meetings, three mothers did not attend at least one of them (D3, D4, D5). In the individualized monitoring, D3 and D4 did not perform IM2 (use of video-feedback), and D2, D5 and D6 did not perform IM3 or IM4. Regarding the level of adherence to the intervention (SAT), with the exception of D3, who attributed the score of 1.0 to their level of involvement, the others attributed scores of 4.0 (D1, D4, D5, D6, D7) and 5.0 (D2). The SAT scores were positively associated with $\mathrm{SE}(.80 ; p<.05)$ in the post-intervention phase and negatively associated with the duration of UE in the follow-up evaluation $(-.85 ; p<.05)$.

\section{Discussion}

The study verified the effectiveness of a short duration intervention with caregivers to promote social engagement in their children with autism. The results of the post-intervention evaluation indicate that the caregivers were able to significantly increase the duration of social engagement (SE) states and also significantly decrease non-social engagement (NSE) states of attention in their children. These gains were maintained three months after the finalization of the intervention.

The increase in SE after the intervention, supported by significant increases in the duration of adult supported joint engagement (SJE) for five of the seven children (D3, D4, D5, D6, D7) and in SJE with symbol infusion (SJE- S) for all the verbal children, indicates that the majority of the caregivers presented high levels of fidelity to the intervention strategies, managing to coordinate their actions with the child and with the shared object, maintaining and expanding the child's focus of attention on the joint activity. In addition, the emergence of coordinated joint engagement (CJE) was registered, with short duration only for the dyads with longer duration of SJE (D1, D4, D7), indicating that with adequate support, the child may go beyond the focus only on the object and incorporate the contributions of the adult, even though not explicitly recognizing the presence of the other person (Adamson et al., 2004). These results confirm those obtained by Adamson, Bakeman, Deckner and Romski (2009), indicating that children with autism show different degrees of SJE, and when verbal, the symbol is integrated into the interaction, either through the verbal expression of the child or the translation of the instructions of the caregiver into actions by the child.

An alternative interpretation to the fidelity of the caregivers for the promotion of the observed changes would be the participation in other care services (OCS). However, the fact that the time spent in OCS was negatively associated with the increased duration of SE, both at baseline and post-intervention, and positively associated with the duration of the unengaged state of attention in the post-intervention and follow-up evaluation, suggests that participation in other care services did not contribute to the changes. The different services (speech therapy, occupational therapy, psychology) occupied between 90 and 300 minutes per week of the children's time and had been attended for at least 12 months, with D3 (score 1.0 in adherence to training) having attended these activities for 27 months. Another point to consider is that these activities are usually only conducted with the child, disregarding the caregiver and the family as adaptation contexts, which can strengthen the children's behavior, whether such behavior is appropriate or not.

Another factor related to the fidelity of the caregivers, and therefore to the results observed in the interactions that followed the intervention, is the degree of adherence to the strategies taught. The score in the scale of adherence to training (SAT) positively associated with social engagement, especially with adult supported joint engagement in the post-intervention, strengthens the assumption that the changes in the interaction patterns of the dyads can be attributed to the fidelity of the caregivers to the intervention strategies. Dyad D3, for example, who indicated a score of 1 for adherence, decreased not only the joint engagement during intervention training, but also presented a slightly significant increase of adult supported joint engagement in the post-intervention evaluation, in addition to a substantial increase in UE in the follow-up evaluation ( $77.9 \%$ of the interaction).

The score of the caregivers in the SAT was negatively associated with the unengaged state (UE) in the follow-up evaluation, suggesting the need for greater attention to this attention state. According to the definition, the function of UE is to explore the environment (e.g., to search for toys), however, from our observations UE also functions as an escape response from the pressures of the context of 


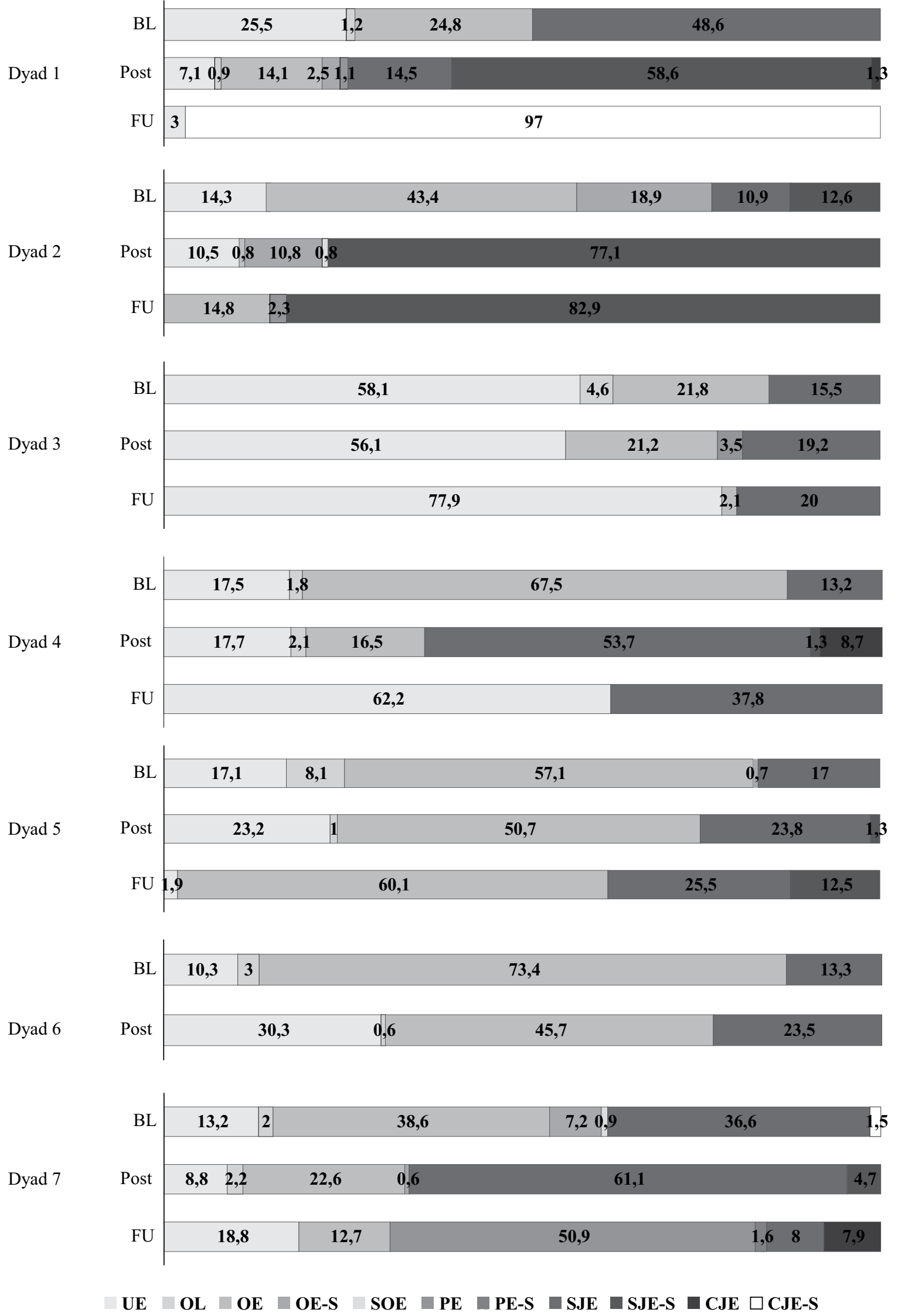

Figure 1. Percentage of the Relative Duration of the attention engagement states observed for each dyad in the Baseline (BL), Post-Intervention (Post) and follow-up (FU) phases. 
interpersonal and/or joint interactions, involving objects and people. Future studies could discriminate these functions, given their importance for the construction of intervention strategies. Unlike OE, the state in which the child is already interacting with the object, UE, especially avoidance, does not provide the caregiver any opportunity to follow the child's focus of attention, requiring the refinement of attention control techniques. Furthermore, for the participants, UE at post-intervention was positively correlated to the age of the child, suggesting that behavioral patterns incompatible with joint engagements may develop with time.

Regarding the adherence of the caregivers, the changes related to the duration of the intervention and the use of a non-controlled environment for the monitoring (residence of caregivers) were sufficient to promote the increase in SE. However, the decrease in the duration of the social engagement, especially in SJE-S in the follow-up evaluation, may suggest an increase in the duration of the individual monitoring or the extension of the use of video-feedback for all the monitoring sessions. Future studies could evaluate these possibilities considering the cost-benefit relationship of the intervention.

The high adherence to the intervention strategies reported by the caregivers may also be related to the use of the engagement states model, which seems to provide a more comprehensive context for the mothers, in which different actions of the partners acquired meaning while they naturally occurred. According to Racine and Carpendale (2007), the different components of joint attention and their functions emerge in circumstances that justify their use, i.e., they emerge in socially contextualized joint activities.

Finally, this study presents further evidence of the competence of caregivers to conduct interventions and encourage the development of the social engagement of their children with autism. It also contributes, within the context of Psychology, with new data regarding the social interaction of children with autism and their social partners and divulges an underutilized but effective intervention model for these children. The fact that an intervention program, developed in another culture, has proved to be effective when applied with Brazilian caregivers over a short period of time suggests that its use can be extended to teachers, therapists or other professionals involved with children with autism spectrum disorders. Thus, it is expected that the results of this study will encourage the development of new studies in different application contexts.

The study presented several limitations to be considered in future research. For example, Kasari et al. (2010) also used an adherence score for the treatment provided by the researchers, while the present study only considered the score that the caregivers attributed to themselves. A second limitation is the absence of language measures that differentiate the aspects of expression and comprehension, since the majority of children who receive the diagnosis of autism remain non-verbal (Adamson et al., 2009).

\section{References}

Adamson, L. B., Bakeman, R., \& Deckner, D. F. (2004). The development of symbol-infused joint engagement. Child Development, 75(4), 1171-1187. doi:10.1111/j.1467-8624.2004.00732.x

Adamson, L. B., Bakeman, R., Deckner, D. F., \& Romski, M. (2009). Joint engagement and the emergence of language in children with autism and Down syndrome. Journal of Autism and Developmental Disorders, 39(1), 84-96. doi:10.1007/s10803-008-0601-7

Adamson, L. B., Deckner, D. F., \& Bakeman, R. (2010). Early interests and joint engagement in typical development, autism, and Down syndrome. Journal of Autism and Developmental Disorders, 40(6), 665-676. doi:10.1007/s10803-009-0914-1

Aldred, C., Green, J., \& Adams, C. (2004). A new social communication intervention for children with autism: Pilot randomised controlled treatment study suggesting effectiveness. Journal of Child Psychology and Psychiatry, 45(8), 1420-1430. doi:10.1111/j.1469-7610.2004.00338.x

Andrade, C. R. F., Béfi-Lopes, D. M., Fernandes, F. D. M., \& Wertzner, H. F. (2011). ABFW: Teste de linguagem infantil nas áreas de fonologia, vocabulário, fluência e pragmática (2nd ed.). Barueri, SP: Pró-Fono.

Bakeman, R., \& Adamson, L. B. (1984). Coordinating attention to people and objects in mother-infant and peerinfant interaction. Child Development, 55(4), 1278-1289. doi:10.2307/1129997

Bakermans-Kranenburg, M. J., van IJzendoorn, M. H., \& Juffer, F. (2003). Less is more: Meta-analyses of sensitivity and attachment interventions in early childhood. Psychological Bulletin, 129(2), 195-215. doi:10.1037/0033-2909.129.2.195

Barton, E. E., \& Fettig, A. (2013). Parent-implemented interventions for young children with disabilities: A review of fidelity features. Journal of Early Intervention, 35(2), 194-219. doi:10.1177/1053815113504625

Charman, T. (2003). Why is joint attention a pivotal skill in autism? In U. Frith \& E. L. Hill (Eds.), Autism: Mind and brain (pp. 67-87). New York, NY: Oxford University Press.

Ingersoll, B., \& Wainer, A. (2013). Initial efficacy of Project ImPACT: A parent-mediated social communication intervention for young children with ASD. Journal of Autism and Developmental Disorders, 43(12), 2943-2952. doi:10.1007/s10803-013-1840-9

Jones, E. A. (2009). Establishing response and stimulus classes for initiating joint attention in children with autism. Research in Autism Spectrum Disorders, 3(2), 375-389. doi:10.1016/j.rasd.2008.08.004

Jones, W., \& Klin, A. (2013). Attention to eyes is present but in decline in 2-6-month-old infants later diagnosed with autism. Nature, 504(7480), 427-431. doi:10.1038/nature12715 
Kasari, C., Gulsrud, A. C., Wong, C., Kwon, S., \& Locke, J. (2010). Randomized controlled caregiver mediated joint engagement intervention for toddlers with autism. Journal of Autism and Developmental Disorders, 40(9), 1045-1056. doi:10.1007/s10803-010-0955-5

Lawton, K., \& Kasari, C. (2012). Longitudinal improvements in the quality of joint attention in preschool children with autism. Journal of Autism and Developmental Disorders, 42(2), 307-312. doi:10.1007/s10803-011-1231-z

Leekam, S. R., \& Ramsden, C. A. H. (2006). Dyadic orientation and joint attention in preschool children with autism. Journal of Autism and Developmental Disorders, 36(2), 185-197. doi:10.1007/s10803-005-0054-1

Meindl, J. N., \& Cannella-Malone, H. I. (2011). Initiating and responding to joint attention bids in children with autism: A review of the literature. Research in Developmental Disabilities, 32(5), 1441-1454. doi:10.1016/j.ridd.2011.02.013

McConachie, H., Randle, V., Hammal, D., \& Le Couteur, A. (2005). A controlled trial of a training course for parents of children with suspected autism spectrum disorder. The Journal of Pediatrics, 147(3), 335-340. doi:10.1016/j.jpeds.2005.03.056

Mundy, P., \& Newell, L. (2007). Attention, joint attention and social cognition. Current Directions in Psychological Science, 16(5), 269-274. doi:10.1111/j.1467-8721.2007.00518.x

Mundy, P., \& Sigman, M. (2006). Joint attention, social competence, and developmental psychopathology. In D. Cicchetti \& D. Cohen (Eds.), Developmental psychopathology: Vol. 1. Theory and methods (2nd ed., pp. 293-332). Hoboken, NJ: John Wiley \& Sons.

Pereira, A. M. (2007). Autismo infantil: Tradução e validação da CARS (Childhood Autism Rating Scale) para uso no Brasil (Unpublished master's thesis). Universidade Federal do Rio Grande do Sul, Porto Alegre, RS.

Racine, T. P., \& Carpendale, J. I. M. (2007). The role of shared practice in joint attention. British Journal of Developmental Psychology, 25(1), 3-25. doi:10.1348/026151006X 119756

State, T. M., \& Kern, L. (2012). A comparison of video feedback and in vivo self-monitoring on the social interactions of an adolescent with Asperger syndrome. Journal of Behavioral Education, 21(1), 18-33. doi:10.1007/s10864-011-9133-x

Tonge, B., Brereton, A., Kiomall, M., Mackinnon, A., \& Rinehart, N. J. (2014). A randomised group comparison controlled trial of 'preschoolers with autism': A parent education and skills training intervention for young children with autistic disorder. Autism, 18(2), 166-177. doi:10.1177/1362361312458186

Vismara, L. A., Colombi, C., \& Rogers, S. J. (2009). Can one hour per week of therapy lead to lasting changes in young children with autism? Autism, 13(1), 93-115. doi:10.1177/1362361307098516
White, P. J., O'Reilly, M., Streusand, W., Levine, A., Sigafoos, J., Lancioni, G., ... Aguilar, J. (2011). Best practices for teaching joint attention: A systematic review of the intervention literature. Research in Autism Spectrum Disorders, 5(4), 1283-1295. doi:10.1016/j.rasd.2011.02.003

Woods, D. (2013). Transana: Qualitative analysis for video and audio data: Version 2.53. Madison, WI: University of Wisconsin-Madison/Center for Education Research. Retrieved from http://www.transana.org/ download/2572253mu39488.htm

Adrine Carvalho dos Santos holds a M.Sc. in Theory and Research of Behavior from the Universidade Federal do Pará.

Marilice Garotti Fernandes is an Associate Professor of the Universidade Federal do Pará.

Ivete Furtado Ribeiro holds a M.Sc. in Theory and Research of Behavior from the Universidade Federal do Pará.

Cleonice Alves Bosa is an Associate Professor of the Universidade Federal do Rio Grande do Sul.

Received: Apr. 25, 2014

1st Revision: Oct. 20, 2014

Approved: Dec. 18, 2014

How to cite this article:

Santos, A. C., Garotti, M. F., Ribeiro, I. F., \& Bosa, C. A. (2015). Intervention in autism: Social engagement implemented by caregivers. Paidéia (Ribeirão Preto), 25(60), 67-75. doi: 10.1590/1982-43272560201509 